\title{
Chapter 7 \\ The Research Pentagon: \\ A Diagram with Which \\ to Think About Research
}

\author{
Angelika Bikner-Ahsbahs
}

\begin{abstract}
Early career researchers often need assistance in their research to help them focus on and systematize relevant aspects of their research. This chapter elaborates the research pentagon as a diagram for reflecting on research. Examples show how the pentagon may represent specific aspects of research, how it allows for (re-)structuring the inquiry process in research, and finally the pentagon is used as an analytic tool to visualize the specificities of the networking of two theories in an empirical case study.
\end{abstract}

Keywords Research pentagon - Diagrammatic reasoning - Abstraction in Context $\cdot$ Interest-dense Situations $\cdot$ Networking of theories

\subsection{Introduction}

An early career researcher in mathematics education is often not well prepared for research. Many young researchers may be prepared for practical teaching rather than for researching, others might come from other academic disciplines going through a paradigm shift (Nardi 2015) while developing a different academic identity. In addition, conducting research with early career researchers is organized and facilitated in various ways (Batanero et al. 1994; Reys and Reys 2017; Liljedahl 2018; Nardi 2015; Haser 2018), for example in graduate programs with a coherent study program or supported by individual supervisors. There are two different types of PhDs, one is built on publishing a number of papers in scientific journals and others follow the aim of writing a monograph as a dissertation thesis. The various ways in which students are involved in research, for instance by a $\mathrm{PhD}$-project, a Masters program or a postdoc position, may manifest quite different needs for support und supervision. Liljedahl (2018) investigated what kind of support PhD students need for their transition from being a dependent to an independent

\footnotetext{
A. Bikner-Ahsbahs $(\bowtie)$

University of Bremen, Bremen, Germany

e-mail: bikner@math.uni-bremen.de

(C) The Author(s) 2019

G. Kaiser and N. Presmeg (eds.), Compendium for Early Career

Researchers in Mathematics Education, ICME-13 Monographs,

https://doi.org/10.1007/978-3-030-15636-7_7
} 
researcher. These students need, besides a peer-community of inquiry, to discuss, reflect, distribute and share their experiences in research; they also need predominantly heuristic tools or examples that help them conduct their own research.

During the last decade I have explored such a heuristic tool, the research pentagon, to find out how useful it is for early career researchers in structuring their research. Originally the research pentagon was created as a diagram to represent five aspects that are necessary to consider in research (Fig. 7.1), namely, research objects, aims, questions, methods and situations (Bikner-Ahsbahs and Prediger 2010).

As is the case for all diagrams (see Peirce 1931-1958, CP 5.162 and also Hoffmann 2005, p. 123-151) the research pentagon may assist to come to new insight, in that early career researchers may first use it to represent the relations between the five research aspects in their research, and then explore the coherence of these relations, justify their suitability, revise the pentagon to improve the research frame, use it to reflect, systematize and restructure research.

In this chapter the research pentagon will be elaborated as an epistemic tool, that is a tool to think-about ("Denkzeug", Schmitz and Groninger 2012, p. 20, own translation) with which early career researchers may elaborate and reflect on their research. Firstly, I provide an understanding of research as a practice of coming to know - a so-called epistemic practice - in a community of researchers. The research pentagon will be embedded into this practice. I then describe the ingredients of the pentagon situated within this understanding of research. Relating it to research examples I substantiate the relevance and suitability of this tool as a heuristic tool for research. This account provides a first impression of what the research pentagon is about, what it allows us to do, and where its limits are. Based on further examples I outline how it may serve to improve a research design. This elaboration then allows us to shift its purpose towards an analytic tool for describing a case of networking theories.

Fig. 7.1 Research pentagon describing main aspects of doing research

(Bikner-Ahsbahs and Prediger 2010)

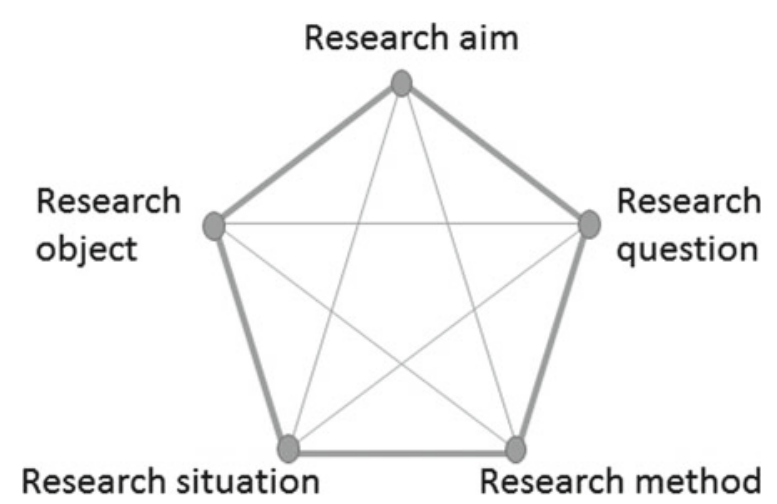




\title{
7.2 The Research Pentagon Embedded in Research as an Inquiry Practice
}

Knorr Cetina (2001) describes scientific practice in contrast to a rule-based practice that addresses routinized handling of ready to hand objects. The latter objects often become invisible while they are used; for example, we are not aware of how a bicycle works while riding it. Such an object is completely different from a research object. A research object is an epistemic object that draws attention by its lack of completeness. But it provides signs of how to further unfold its nature, hence, has the potential to generate meanings about itself. A researcher exploring such an object enters into a relationship with it by the epistemic practice of unfolding these meanings in a "dynamic, creative and constructive" way (Knorr Cetina 2001, p. 187). This is just how the present paper considers research, as an epistemic inquiry unfolding the research object as an epistemic object. Thus research is built on a meaning generating relationship between researcher and an epistemic object.

Interestingly, a paper by Boaler et al. (2003), written to describe research practices that are relevant for early career researchers to build, does not address these epistemic objects explicitly. Instead they describe research as practice in which knowledge is strategically used:

\begin{abstract}
Research, after all, is not knowledge. Research, whether empirical, theoretical or philosophical, is an active process of investigation, one that relies on strategic use of knowledge, in context. Because it is something people do, not just know, we turn next to examine a small but illustrative set of core practices of research: reading, formulating a research question, using data carefully to make and ground claims, moving from the particular to the general, considering mathematics, and communicating research findings. (p. 495)
\end{abstract}

All these specific practices, reading, making claims, communicating etc., are important parts of research as an epistemic practice as was defined above. But what is to be added to this description is the epistemic nature of the object under investigation, which because of its lack of completeness provides signs for its exploration, and evokes problems to be solved. For that reason the first two aspects of our research pentagon (Fig. 7.1) are the research aim and the research object (Mason and Waywood 1996). The aim comes from a problem, which indicates the kind of relevance-why a study of the specific research object is done. But a research object is rarely completely defined at the beginning. For a research study to be conducted there is a necessity to clarify the research object's nature repeatedly, based on research already done in the field, theory available, and finally, based on the results obtained. Let us consider an example Boaler et al. (2003) have used to illustrate their considerations.

The Third International Mathematics and Science Study TIMSS (Baumert and Lehmann 1997) investigated and compared students' curricular mathematical knowledge in different countries. This comparison showed that Japanese students scored much more highly on the items than students from Germany or the United States, which means the average level of curricular mathematical knowledge differed among the three countries. Here the object of research is clear, namely, 
students' mathematical knowledge described by an average score based on solving mathematical tasks in different mathematical domains. These TIMSS results called for a better understanding of how teaching takes place in the three countries. This research aim was addressed by Hiebert et al. (1999) in the follow-up TIMSS video study (see Fig. 7.2). They posed the research question "How is mathematics taught in the United States, Germany, and Japan?" (see Boaler et al. 2003, p. 497; Hiebert et al. 1999, p. 196), switching the epistemic object to the kinds of teaching of mathematics at grade eight in these countries. The underlying assumption is that teaching influences how students understand mathematics. In their study, Hiebert et al. (1999) identified clear differences in the national teaching scripts of the three countries, shaped by "cultural teaching patterns" (p. 200) with differences in the quality of teaching for understanding (p. 200), in the role of the teacher, in the kind of mathematics that is taught, and in the expected students' behavior. Thus after the study, the view on teaching, the research object, had changed. Hiebert et al. stated that "teaching is a cultural activity ..." (p. 196). The differences in teaching could now be understood as a consequence of the culture of schooling and "cross-cultural differences in the individual features of mathematics teaching must be understood within the cultural system of teaching of which they are part" (p. 200).

Summing up, three aspects are important to consider in research as an epistemic practice of inquiry (Fig. 7.1). The epistemic practice is related to an epistemic object, the research object, which is investigated to follow a research aim or solve a problem. This aim is partly addressed by a research question that directs the investigation of the research object. However, the research object may change its nature in the course of research.

Boaler et al. (2003) emphasize two further aspects that are relevant for research. Firstly, the choice of research method (Figs. 7.1, 7.3) must perfectly fit the research question to be answered. Indeed, only their methodical decisions of how a video study should be conducted as a large-scale comparison study between the three countries enabled Hiebert et al. to unfold the cultural characteristics of teaching; for example they had to find curricular topics related to the same grade that allowed

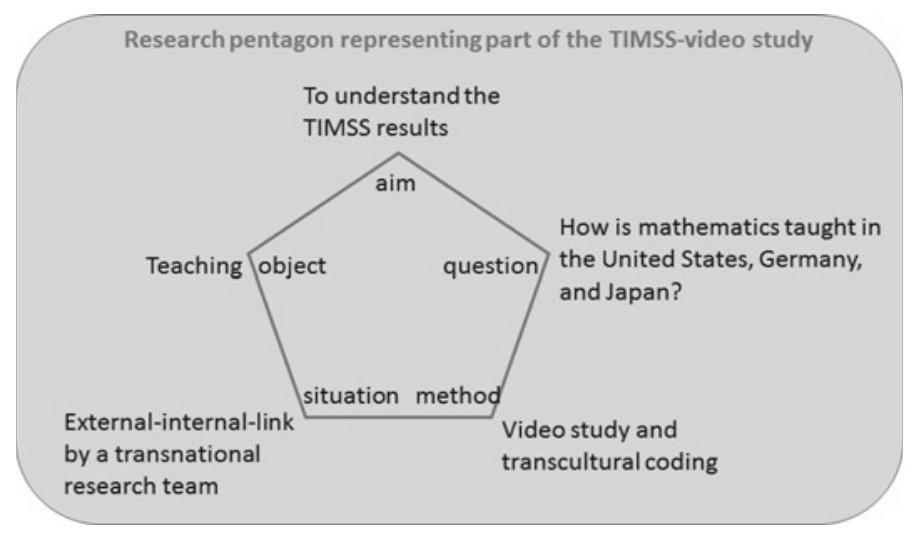

Fig. 7.2 Aspects of research of the TIMSS video study 


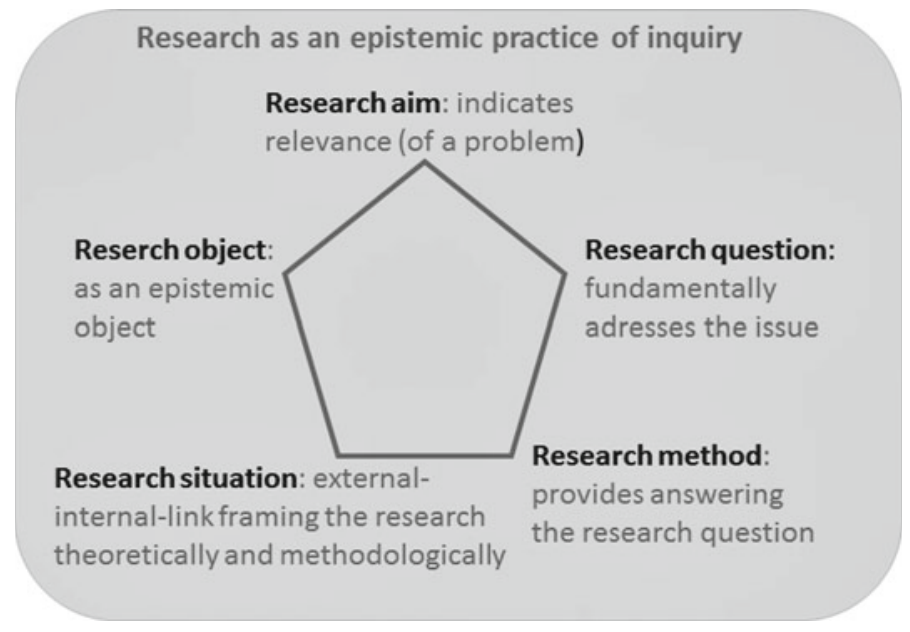

Fig. 7.3 The Research pentagon (Bikner-Ahsbahs and Prediger 2010, p. 487)

them to compare several classes and teachers in the schools along the school year. Also detailed technical decisions, such as where to put the camera, were important steps towards comparison. Secondly, researchers must become deeply familiar with the research area and the theoretical background in which the study and its methodology are embedded. The latter holds true for the theoretical as well as empirical knowledge in the specific area, which allows for framing the research in order to build a research situation (Fig. 7.2) for the investigations to be done. In the TIMSS video study, Hiebert and Stigler built a transnational research team with as much knowledge about the teaching in the three countries as possible, to be strategically used, for example, for identifying comparable transnational codes.

The research question normally is the driving force for conducting a successful study. So, what makes a question a good research question? Boaler et al. (2003) claim that

One obvious characteristic is that, at their core, they [Hiebert \& Stigler] get at a fundamental issue. These researchers framed and asked questions that were central to the puzzles and problems of the field in which they were working. A second characteristic of these questions is the 'fit' between question and the method. (p. 320)

The main criterion Boaler et al. stress, is digging deeply into the core concept that fundamentally solves the problem. Taken as a paradigmatic example, the research question from the TIMSS video study directly focuses on the core of solving the problem of understanding the differences of the TIMSS results from the perspective of teaching. Hiebert and colleagues unpacked the characteristics of teaching in their comparison study and revealed teaching scripts as new epistemic objects, that highlighted what could not be thought of before. As culturally determined practice, teaching scripts cannot just be transferred from one country to another; they come out of the cultural heritage of schooling in the country. 
Thus, the research method should perfectly fit the research questions and both should refer to the research situation in the field (Fig. 7.3). The research situation consists of an external as well as an internal part. The external research situation comprises the discourse in the field to be explored by reading and attending conferences. The choice of theoretical knowledge and empirical results taken therefrom must fit not only the methodical procedure, but first and foremost it is the basis for the definition of the research object and it even comes prior to the choice of method. The internal research situation addresses the situation in which the study is undertaken, framed by the knowledge taken from the field. It must also fit the role of the researchers who may directly be involved in research; for example, in participatory research their role is different from that in a large scale study where objectivity is a standard to be followed, as in the TIMSS video study. It was the idea of establishing a transnational research team that enabled Hiebert and colleagues to link the external and the internal research situations, in order to bring the national knowledge about teaching from the three countries into the internal research situation of the study, for example to find comparable codes across the countries (Fig. 7.3).

In most cases, only one research study is not sufficient to fully reach the research aim or solve the problem. The reason for this is that a broad and general aim has to be broken down into answerable research questions, which may address just a specific view embedded into a narrow framework. This must not be taken as a disadvantage. On the contrary, a narrow view that at the same time still allows a general answer to be revealed (as emphasized by Boaler et al. 2003) may provide in-depth insight.

Further, with each theoretical background assumptions also enter the scene, which are not shown in the pentagon but which are equally important as a prerequisite for a coherent framework. Knowing the field helps the researcher to make good and suitable choices. Therefore, constantly re-considering the research situation while reading about the knowledge in the field, should be an ongoing activity. This activity might assist in unfolding the nature of the research object more lucidly so that research questions may also become clearer, and so that the methods may be better adapted both to the research object and to the research questions. The interrelated revision of the specific research pentagon in turn might improve the coherence of the research framework as a whole. These processes not shown in the pentagon are additionally important for communicating research finally, for example to better draw conclusion from the results and, hence, provide connectivity back to the research field.

\subsection{The Research Pentagon as a Model for Practicing Research}

\subsubsection{Hidden Views on Formulas}

As described in the previous section the research pentagon consists of five aspects necessary to be considered in research. In this section, I refer to a study conducted 
by Schou and Bikner-Ahsbahs (submitted), in order to illustrate a pathway that established the research study and is illustrated by the pentagon in Fig. 7.4.

Research often starts with a problem that gives rise to a research aim. The aim might come from a practical problem, a gap identified in research or a new situation in school as society has changed or a reform has taken place. In the example about unpacking students' hidden views on formulas, we (Schou and Bikner-Ahsbahs) started with the problem of students' difficulties when formulas are used. This problem is a practical problem as well as a problem that research has addressed in many specific but rarely general ways. For example students fail to use the right formulas in a particular context or they use the right formula in a wrong way. From there, the research aim was set up to provide explanations of the students' difficulties and to improve the teaching when formulas are involved (see aim, Fig. 7.4).

In order to solve this problem an intense literature review in the external research situation, the research field, had to be done to find out what was already known about the problem in the field. We found out that handling formulas are rarely addressed beyond a specific area and that there can be a variety of ways students handle formulas, for example, as a function (Malle 1993) or as an algorithm for calculating a measure (Siller and Roth 2016). This knowledge was used to prepare a lesson series on geometric formulas providing various resources for the students; from this series several kinds of data were collected (see method, Fig. 7.4).

To take into account a broad variety of views on formulas, the term formula had to be broadly defined. Thus, the research object was described as a comprehensive understanding of ways to handle formulas. But what does it mean, to understand ways to handle formulas? This understanding is shown by acting when students solve a task with all kinds of semiotic resources, inscriptions, material models, diagrams, or dynamic representations at the computer (external situation). In addition, we had to come back to where the problem is located, the classroom, where the teacher rather works with groups than with individuals (see aim, Fig. 7.4). For both reasons a socio semiotic perspective was adopted (back to external research situation, Fig. 7.4). It allowed us to include semiotic means as well as the social situation of group work in the classroom (inner/internal research situation, Fig. 7.4). This perspective then was the lens through which we captured

Fig. 7.4 Research pentagon of the "hidden views on formulas" (cf. Schou and Bikner-Ahsbahs, submitted)

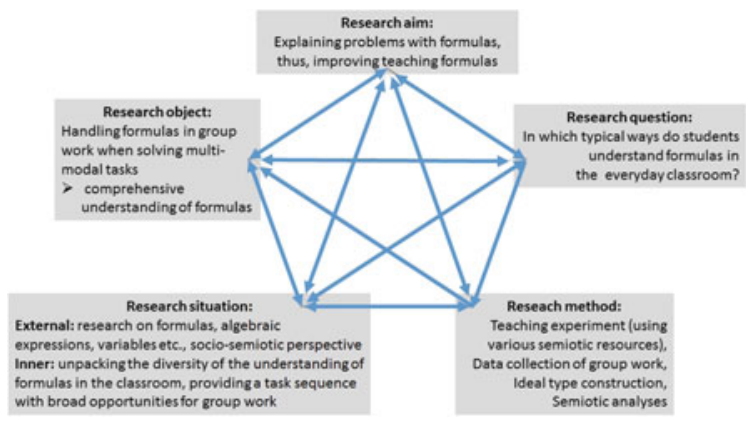


the research object more precisely, namely, a comprehensive understanding of formulas in the classroom (research object again, Fig. 7.4). Thus, the considered situation to be researched is the internal research situation, which had to be consistent with the socio semiotic perspective we had chosen. Since we wanted to unpack the diversity of hidden views on formulas in the classroom and clearly conceptualize these hidden views, our research question asked for typical ways of how students understand formulas in the classroom, including the definition of the research object. By the methodical decision of building ideal types empirically (Bikner-Ahsbahs 2015), we precisely were able to answer the research question. The Ideal Types were built by identifying typical situations in the classroom in which a formula is handled in similar ways. This similarity is idealized towards the core idea of the specific understanding. We obtained an ideal type that does not depend on the situation anymore (method and inner research situation, Fig. 7.4). For example a formula may be understood as an algorithm to calculate a magnitude by inserting measures into an expression (research object, Fig. 7.4). This may of course happen in many situations.

To keep close to the original aim to gain knowledge for the classroom, a teaching experiment with group work was conducted and observed: the videotaped group work was analyzed for uncovering hidden views of understanding formulas (method and inner research situation, Fig. 7.4). After analyzing the data the discussion came back to the aim to clarify how far the research question could be answered and how far this answer contributed to achieve the aim.

Table 7.1 represents the research path described above; which is built by the five research aspects. It shows that at the beginning, single research aspects are considered one after the other going back and forth. As the work proceeds more and more aspects are considered together. A glance at Fig. 7.4 makes clear that finally all connections between the five research aspects are included in the research.

Looking back, the research object seems to have been stable throughout the research process from the beginning. But this was definitely not the case. It was the most difficult part of the study because its definition required it to be precise and at the same time to allow for generalizing our results that were to be gained just by a case study. This had consequences for all the aspects, because all five aspects are deeply intermingled and changing one aspect changes the view on others, or even involves changing others, too. This interdependence is represented by diagonals in the pentagon.

Table 7.1 Chronological research path addressing research aspects

\begin{tabular}{|c|c|c|c|c|c|c|c|c|c|c|c|c|c|c|}
\hline \multicolumn{15}{|c|}{ Research path } \\
\hline aim & $\begin{array}{l}\text { exter- } \\
\text { nal } \\
\text { situa- } \\
\text { tion }\end{array}$ & $\begin{array}{l}\text { me- } \\
\text { thod }\end{array}$ & ob- & $\begin{array}{l}\text { exter- aim } \\
\text { nal } \\
\text { situa- } \\
\text { tion }\end{array}$ & $\begin{array}{l}\text { exter- } \\
\text { nal } \\
\text { situa- } \\
\text { tion }\end{array}$ & $\begin{array}{l}\text { inter- } \\
\text { nal } \\
\text { situa- } \\
\text { tion }\end{array}$ & $\begin{array}{l}\text { ob- } \\
\text { ject }\end{array}$ & $\begin{array}{l}\text { inter- } \\
\text { nal } \\
\text { situa- } \\
\text { tion }\end{array}$ & $\begin{array}{l}\text { ques- } \\
\text { tion }\end{array}$ & $\begin{array}{l}\text { ques- } \\
\text { tion, } \\
\text { ob- } \\
\text { ject }\end{array}$ & $\begin{array}{l}\text { me- } \\
\text { thod }\end{array}$ & $\begin{array}{l}\text { me- ob- } \\
\text { thod, ject } \\
\text { inter- } \\
\text { nal } \\
\text { situa- } \\
\text { tion }\end{array}$ & $\begin{array}{l}\text { aim, } \\
\text { me- } \\
\text { thod, } \\
\text { inter- } \\
\text { nal } \\
\text { situa- } \\
\text { tion }\end{array}$ & $\begin{array}{l}\text { aim, } \\
\text { ques- } \\
\text { tion }\end{array}$ \\
\hline
\end{tabular}




\subsubsection{Language Demands in Qualitative Calculus}

With reference to her paper, Dilan Şahin-Gür (Sahin-Gür and Prediger 2018) re-interpreted her research pentagon that she had presented at a summer school. After applying it to her own research on a design-based research study on language demands in qualitative calculus, she could offer interesting comments on her experience with working with the research pentagon, specifically according to its limitations. She agreed to include a part of it in this paper in order to show her use of the pentagon in progress.

The first interesting point is the way Şahin-Gür has re-interpreted the diagram (Fig. 7.5). In our view, this is a necessary step to make the pentagon become one's own tool for research. Naming the research aim as an "overarching question" is really an interesting way to perceive this aspect since research aim and research question are often not clearly distinguished. Although in some research studies aim and question may be interchangeable, a PhD thesis is generally not meant to solve the huge problems in our field with just one study. So it is most reasonable to distinguish the two aspects in the manner Şahin-Gür has stressed them. The research object is not re-described by her, it might have been much clearer than in our study. "Remember to set your needle" means that the needle should link the inner and outside research in order to keep the research frame coherent, that means to connect and embed one's own research in the field's knowledge but also vice versa to consider the knowledge of the field within one's own research, hence, shaping the empirical setting coherently. Equally interesting is the comment about the function as well as the limits of the methods chosen. The function of the method for her is to answer the questions and fit the whole framework, including

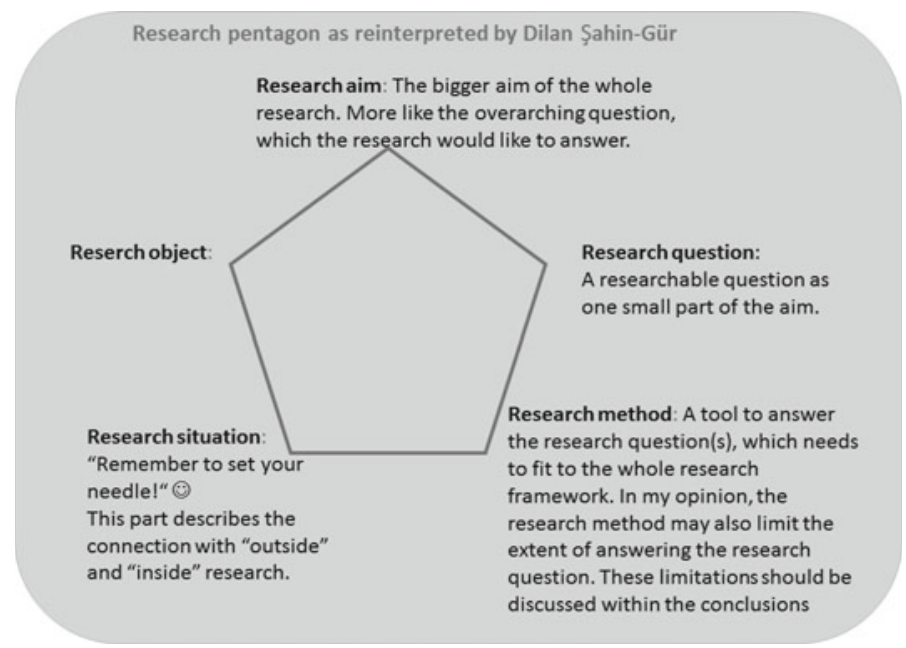

Fig. 7.5 Research pentagon re-interpreted by Dilan Șahin-Gür, from an email exchange, 19 October, 2018 


\section{Research pentagon as used by Dilan}

Research aim: (1) Designing language- and mathematics-integrated (learning) arrangements for calculus education. (2) Developing empirically grounded local theories of students' learning processes and the occurring language demands.

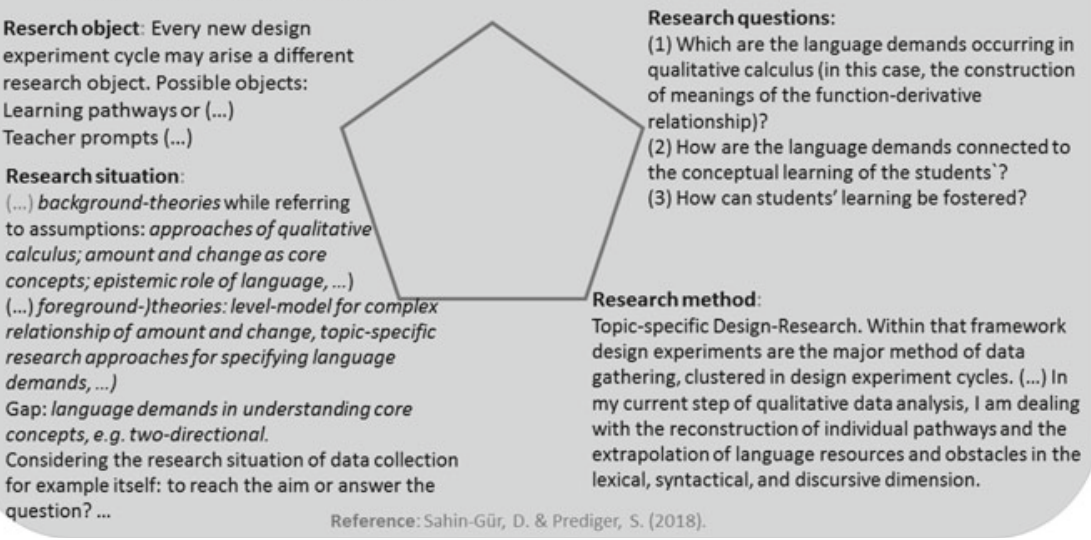

Fig. 7.6 Research pentagon related to language demands in qualitative calculus (worked out by Șahin-Gür, based on: Sahin-Gür and Prediger 2018)

methodical limitations that allow only partial answers to the research questions. Here a responsibility of researchers is addressed, namely to communicate methodical limitations.

Let us now come to the version of Şahin-Gür's individual Pentagon (Fig. 7.6) as it represents the current status of her research. The study is "Topic-specific Design-Research", which is also the research method she has chosen. This choice seems very clear. Typical for such a study is the way the research object is described; there are many research objects dependent on the cycle and the status of the development, hence they are not specified. Evenly typical for a design study are the three questions Şahin-Gür has set up: one question is about the demands, the second one addresses the link to conceptual learning, that is the learning goal, and the final one aims at identifying fostering conditions or means as tools to be designed. What seems specifically important for Şahin-Gür at this stage of research is the research situation, to think of a background theory (for example constructivism) including assumptions, and what kind of foreground theory (for the notion of background and foreground theory, see Mason and Waywood 1996) she is currently thinking of, a kind of "level-model for complex relationship of amount and change, topic-specific research approaches for specifying language demands".

Şahin-Gür provided some reflection on her working with this diagram, addressing the following question: How does this pentagon help me in my research process? She wrote as follows:

(...) Only when I had filled the vertices (at least roughly), I was able to think (deeply) about the relationships between the vertices and so sharpen/refine my Pentagon. By taking a structured look at my work (now visualized in the pentagon), I have understood which vertices remain almost unchanged (e.g., the overarching research aim and methodological 
framework), which become more and more defined (e.g., the research situation, in particular the foreground-theories) and that the research questions and methods of data analysis can change completely by looking at another design cycle.

(...) What the Pentagon cannot do in its present form is to illustrate the complexity of a work (its depth) and to accompany the processuality of the research process, at least not a single Pentagon. This is not to be expected when working with the Pentagon, but a powerful tool for structuring and for building consistency in your research. (Dilan Sahin-Gür, from an email exchange, 19 October, 2018, section in the original)

\subsection{The Research Pentagon Illustrating a Case of Networking of Theories}

In the next two sections I use the research pentagon again, but this time as an analytic tool for a case study on networking theories, in order to make visible what the networking of theories is about. The study was undertaken with two Israeli research teams led by Tommy Dreyfus and Ivy Kidron (Bikner-Ahsbahs and Kidron 2015). It will be shown that the pentagon is useful to clarify the notion of the networking of theories. Since theories are addressed, our notion of theory is explained in this section. Referring to the cultural semiotics of Lotman (1990), Radford (2008) has provided a suitable concept of theory embedded in a socio-historical and cultural view that helps to clarify what we mean by the term theory:

More specifically, I want to suggest that a theory can be seen as a way of producing understandings and ways of action based on:

- A system, P, of basic principles, which includes implicit views and explicit statements that delineate the frontier of what will be the universe of discourse and the adopted research perspective.

- A methodology, M, which includes techniques of data collection and data-interpretation as supported by $\mathrm{P}$.

- A set, $\mathrm{Q}$, of paradigmatic research questions (templates or schemas that generate specific questions as new interpretations arise or as the principles are deepened, expanded or modified). (p. 320, emphasis in original)

For Radford, a theory is for research and constitutes a specific language that is shared in a research community based on the set of shared principles, methodologies and paradigmatic questions that show what kind of questions are researched. The theories' principles are not questioned but can (and should) be at least partly made explicit. The methodology belongs to the theory in that it encompasses decision rules based on the principles that allow for a preference for choosing specific methods rather than others suitable for answering the paradigmatic questions. He uses the triple (P, M, Q) as a short description of theory and emphasizes its dynamic nature that develops through research revealing results $\mathrm{R}$. Radford represents this developmental nature of theories by [(P, M, Q), R] (Radford 2012). I illustrate this concept of theory by the use of two examples, Abstraction in Context (AiC) and the theory of Interest Dense Situations (IDS). 


\subsubsection{Abstraction in Context (AiC)}

The set of principles of AiC (Dreyfus et al. 2015) consists of basic assumptions, models and concepts that describe a process of constructing abstract mathematical knowledge that individuals might go through when confronted with a mathematical task or a mathematical situation. Such a process of abstraction is regarded as a human activity that takes place in a specific context. For example the activity of how to assign a value to a continued fraction (see below) takes place in a specific context including the learning arrangement, the tasks, the social situation (e.g., group work or working in pair), probably a calculator, other artifacts, the students' personal learning history, etc. Referring to the concept of vertical mathematizing by Treffers (1987), the process of abstraction consists of a vertical reorganization of previous constructs into new ones by making connections (Davydov 1972; Freudenthal 1991). It takes place in three stages of abstraction (Hershkowitz et al. 2001; Dreyfus et al. 2015):

- Stage I: there is a need for a new construct (NNC).

- Stage II: this need drives a process in which a new construct emerges. This process is described by an epistemic action model, the RBC-model (see below).

- Stage III: This new construct is consolidated (thus $+\mathrm{C}$ is added to the name of the epistemic action model: $\mathrm{RBC}+\mathrm{C}$-model).

The RBC-model ( $\mathrm{R}$ stands for recognizing, $\mathrm{B}$ for building-with and $\mathrm{C}$ for constructing, these abbreviations indicate the kind of epistemic action) of stage II consists of three epistemic actions:

- Recognizing previous constructs as relevant for the current task or situation.

- Building-with a previous construct with the purpose of solving a problem, making a justification, etc.

- Constructing is the action that takes place when a new (to the learner) mathematical construct emerges.

These three epistemic actions are nested (Fig. 7.7), which means that constructing already includes building-with constructs and recognizing a known construct, whereas building-with also encompasses recognizing a previous construct.

The methodology that is used to analyze the steps shown by the students' actions when they work on a task is intimately linked to the $\mathrm{RBC}+\mathrm{C}$-model. The epistemic actions can be observed in the students' utterances and actions with artifacts,

Fig. 7.7 Illustration of the nested structure of the RBC-model

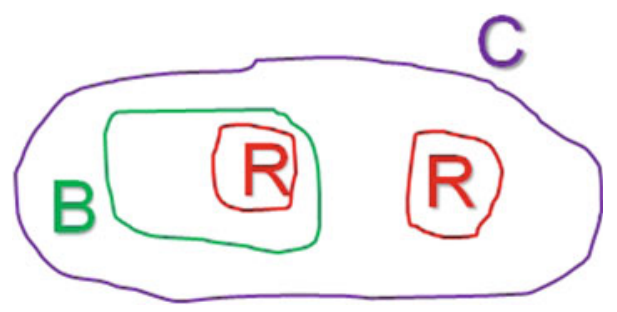


gestures used, etc. To analyze the epistemic processes, data are needed that capture them, for example, video recordings and transcriptions. The key part of a process of abstraction is the emergence of a new construct. In order to specify the new aspects of the construct clearly, an a priori analysis is conducted before the research, and after the research it is investigated how the final result differs from the prediction or confirms it, and why.

Paradigmatic questions are related to the parts of the theory, for example: How is specific knowledge constructed? How is the process of constructing knowledge determined by the context? How does the need for a new construct (NNC) impact the process? How does consolidating take place?

\subsubsection{Interest-Dense Situations (IDS)}

The theory of interest dense situations has been developed to identify situations in mathematics classrooms that are likely to foster situational interest. This kind of interest emerges dependent on the situation. It is kept for a while, but when the situation changes this kind of interest disappears normally. The question was how situational interest can be held in the mathematics classroom. Mitchell (1993) found that situational interest can be held if students become involved in an activity which is meaningful to them. In interest dense situations, this activity encompasses a process of constructing mathematical knowledge that emerges within social, mathematically oriented interactions by means of acting together in an interactive way. An IDS is a situation in which many students show interest, that is they are involved in the epistemic process of generating mathematical meaning, an activity that is meaningful to them (Bikner-Ahsbahs 2005; Bikner-Ahsbahs and Halverscheid 2014; Kidron et al. 2010).

An interest dense situation (IDS) is a situation of generating mathematical meaning as an activity of answering a mathematical question or solving a mathematical problem. Three features characterize these situations: the students

- are socially involved intensively in the activity,

- deeply participate in the epistemic process of advancing insight,

- attribute high value to the experienced mathematical activity.

Also in IDS there is an epistemic action model, the gathering-connectingstructure-seeing model (GCSt-model, G stands for gathering, C stands for connecting and St for structure seeing), which describes the process of knowledge construction by three epistemic actions; however, they need not be nested.

- Gathering similar mathematical meanings, ideas and signs for a mathematical situation as heuristic strategy;

- Connecting: relating to each other a few of the above meanings, ideas and signs as heuristic strategy;

- Structure seeing: Becoming aware that a specific relationship is paradigmatic for a much larger set of cases (seeing the general). 
Structure seeing may lead to new knowledge but it also happens if the students already know a structure but reconstruct it in a new context. In this model knowledge is not stored anywhere. When students become involved in a social process of knowledge construction, they may re-construct a mathematical idea they have met before. Each IDS leads to structure seeing as this is the step when students experience and express advancing insight.

The main part of the methodology is ideal type construction (see Bikner-Ahsbahs 2015; see also Sect. 7.3 in this chapter) to reveal how knowledge construction typically takes place and what conditions foster or hinder it. However, this theory is open to further methodical decisions as long as they fit the principles and paradigmatic questions.

The paradigmatic questions of IDS focus on processes of knowledge construction in groups: What conditions foster or hinder such processes? For example, what can be said about semiotic tools, the role of the teacher, types of interactions and the emergence of situational interest?

\subsubsection{Comparing and Contrasting the Two Theories}

Before networking the two theories let us focus on their commonalities and differences. Their commonalities can be condensed in the following three principles:

- Epistemic acting reveals knowledge;

- Knowledge is constructed during involvement in solving problems, working on tasks or answering questions;

- Epistemic models are used as scientific tools to describe and investigate empirically, on the micro-level, how mathematical knowledge is produced and made accessible.

Core differences of these theories are described as follows:

- AiC regards knowledge constructing predominantly as an individual process, which may be related to a process of knowledge construction to another individual, whereas IDS regards knowledge constructing as a social process.

- Whereas the individual in $\mathrm{AiC}$ interacts with the given context, the social group in IDS reconstructs relevant aspects of their social semiotic environment given in the process of knowledge construction together with their knowledge construction; hence, they make explicit what they use and why.

\subsubsection{A Case of Networking Between AiC and IDS}

Let us now turn to a case of networking two theories. This case was first published by Kidron et al. (2010), and worked out in-depth by Bikner-Ahsbahs and Kidron 
(2015). It is based on the two theories, AiC published by Hershkowitz et al. (2001) and IDS described above, published by Bikner-Ahsbahs (2005). Let us now use the research pentagon to describe this process of networking as an example.

The authors took the theories to frame the internal research situation of considering both theories together. The research problem they considered linked the two theories: IDS describes social situations of constructing mathematical knowledge that foster the emergence of situational interest, but the precise mechanism of how interest is fostered through the epistemic process was not clear. On the other hand, AiC allows for considering and identifying the need for a new construct in a process of constructing new knowledge that could play a fundamental role. Taking both theories into account, the research question was as follows: How is the need for a new construct related to the emergence of situational interest? The research object was twofold, the phenomenon of the emergence of situational interest in IDS as well as the phenomenon of the emergence of an NNC. Both theoretical perspectives were expected to consider the research object as a two-fold phenomenon. The aim was to clarify the role of the theories in this research in terms of their principles, methodologies and paradigmatic questions based on empirical research.

Following the commonalities of the two approaches, the first step in the networking process was to develop a task allowing for collecting data that made sense from the two perspectives. In our case, we chose a continued fraction task (see Kidron et al. 2010; Bikner-Ahsbahs and Kidron 2015). Five steps were conducted in a so-called cross-methodology involving task design, piloting the task, data preparation, data analysis and reflection on the whole process. To coordinate the two theories every step encompassed a series of five cross-over stages in the networking process; we list these and briefly illustrate them for the first step, task design. The teams decide cooperatively (e.g., about task topics), process separately (e.g., concrete developing of tasks according to each theory), exchange and working with results from the other theoretical view (e.g., the tasks from the other theory groups), rework their own results (e.g., revising their own tasks), and build consensus. Figure 7.8 shows one of the task sequences that was used for a task-based teaching interview with Tim and Matt (grade 10), Figs. 7.9 and 7.10 shows the students' written answers to task 3 and task 4, and Figs. 7.11 and 7.12 to task 5 .

Before the networking of the theories is presented in more detail, the students' epistemic process is illustrated by using the two models, the RBC-model from the AiC-perspective, and the GCSt-model from the IDS-perspective.

In the first two tasks the students calculate the first three continued fractions. Addressing the task symbol by symbol, they gather mathematical meanings (Fig. 7.9), and then they do not build $f(3)$ by calculating but by using $f(2)$, hence they connect $f(3)$ with $f(2)$. Figure 7.10 shows that the students achieve structure seeing going through task 3 and task 4, shown in the answer to task 3 and task 4 translated in the caption of Fig. 7.10: The students identified and explained two patterns of how to expand the continued fractions arithmetically, adding the same amount at the bottom or on the top.

The following solving phase is described using the RBC-model, leading to a new construct which the students called "Space of places". 


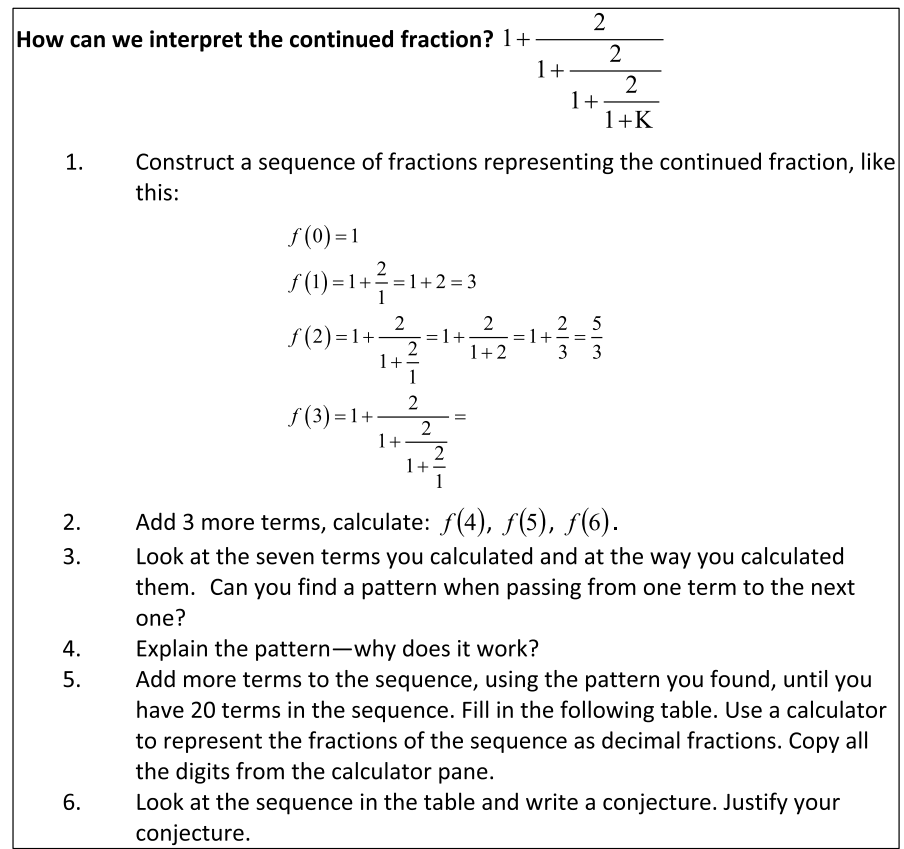

Fig. 7.8 The first six of eight tasks about a continued fraction (Kidron et al. 2010, 2011, p. 2452; Bikner-Ahsbahs and Kidron 2015, p. 238)

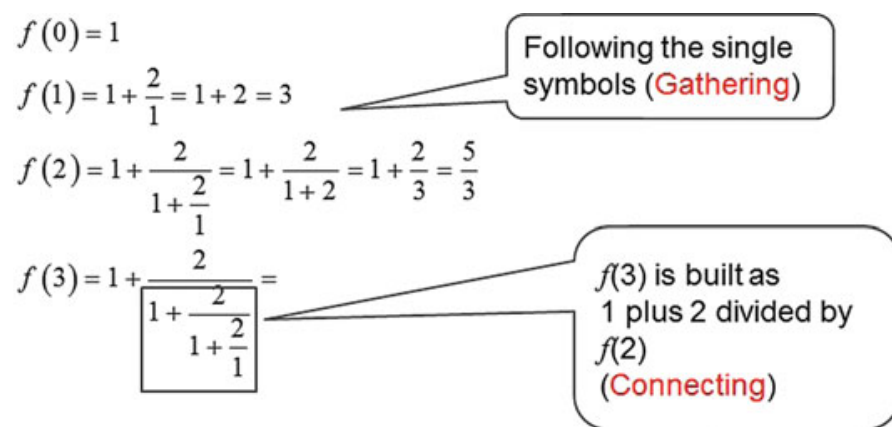

Fig. 7.9 Examples for the IDS epistemic actions gathering and connecting

Matt and Tim recognize in their calculation previous constructs as relevant, namely, two subsequences made of decimal fractions (Fig. 7.11). By building-with, they consider two alternating subsequences, an increasing and a decreasing sequence. 

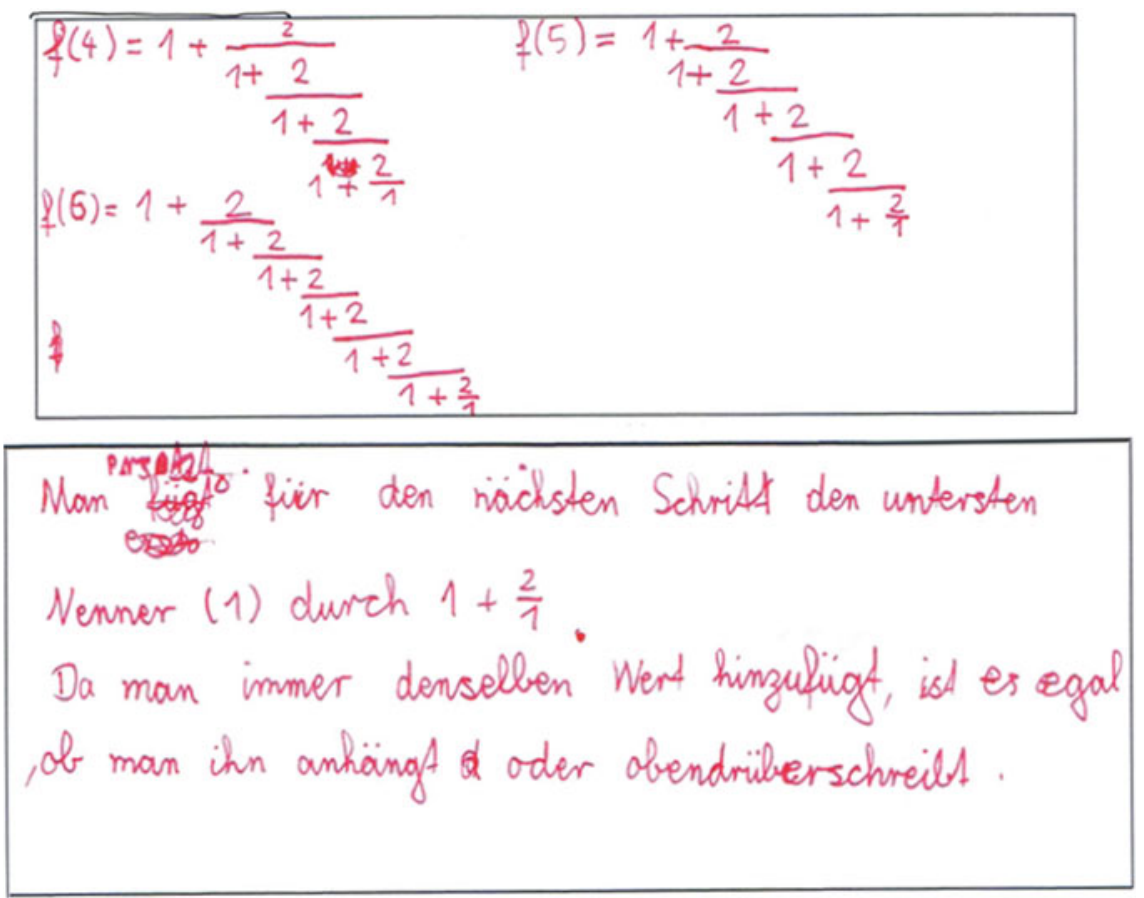

Fig. 7.10 Structure seeing is shown: "For the next step, one replaces the lowest denominator (1) by $1+2 / 1$. Because one always adds the same value it does not matter whether one tacks it on or writes it on top" (translated)

Based on the calculation of $f(7)$ to $f(19)$ (Fig. 7.12) and the following eight interpretations, the students reveal a new construct, which is still a bit vague:

- There are two subsequences of values of $f(n)$.

- One increasing subsequence of numbers smaller than 2.

- One decreasing subsequence of numbers larger than 2.

- In the increasing sequence the number of decimals after the decimal comma equaling 9 grows.

- In the decreasing sequence the number of decimals after the decimal comma equaling 0 grows.

- They begin referring to a notion they call "space of places".

- With this notion they refer to the growth of the space of places.

- They conjecture it might be growing with the square root of $n$.

Together the students invent the notion the space of places for a phenomenon they observe, but at this point the meaning of it is not so clear. What is clear, though, is that this notion is used to capture the regularity in the repeating of digits after the decimal comma. Figure 7.12 illustrates that either zero or nine are repeated depending on the subsequence. 
Fig. 7.11 Students' solution of task 2; arrows, rectangle and circles added by the researchers

Fig. 7.12 The written solution of Tim and Matt to task 5 using a calculator. (See Bikner-Ahsbahs and Kidron 2015, p. 240)

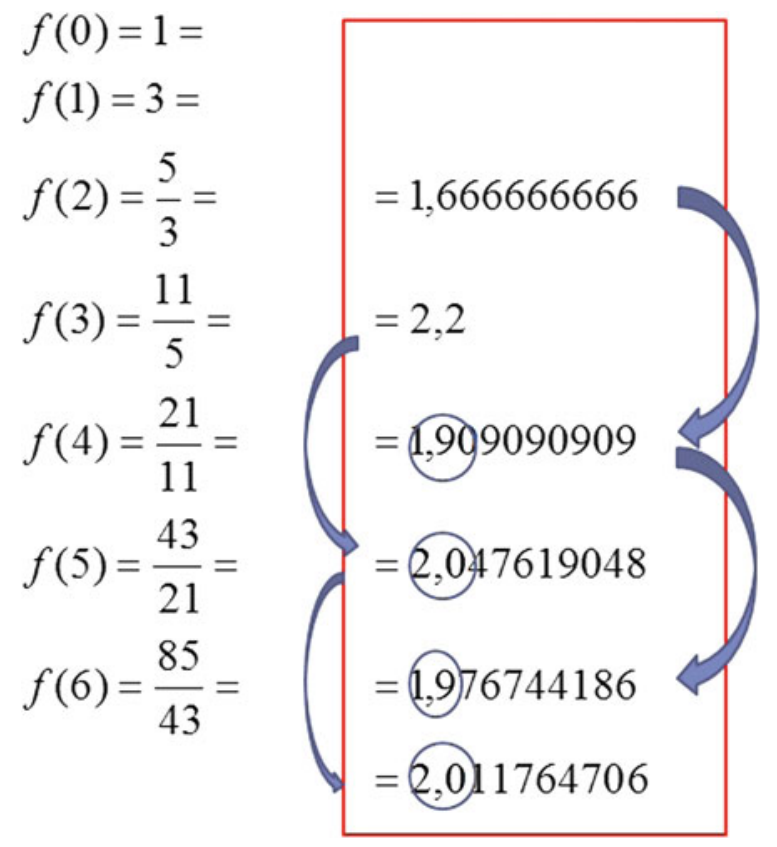

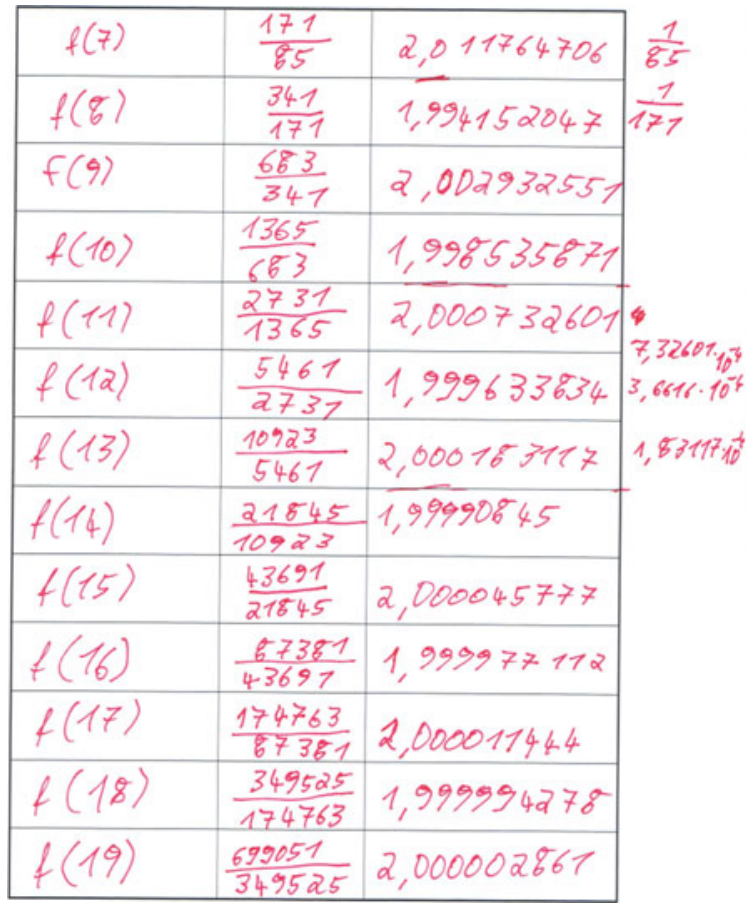




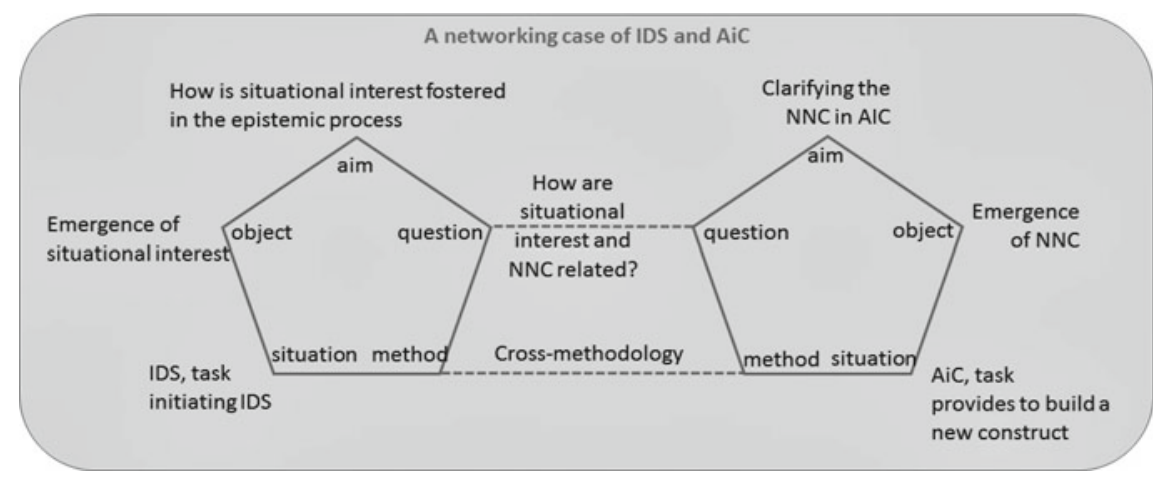

Fig. 7.13 The IDS-pentagon and the AiC-pentagon of a networking case

Let us now use the research pentagon to explore the networking of theories as described above in its two final steps.

In Fig. 7.13 two research pentagons are used to represent the research aspects for each of the two theoretical perspectives. The aspects represented by the vertices have been outlined in Sect. 7.2. Now, two theories are coordinated according to the research question, which links the research from the two views, and the method, which involves a coordinated cross-exchange along the empirical procedure (step four of the cross-methodology). This procedure is worked out in detail (see Kidron and Bikner-Ahsbahs 2015). Here I reduce the description of the networking of theories in order to present the results of this research. These results have shown that the need for a new construct (NNC) does not always appear at the beginning of the process of abstraction, but in our data mostly rather late. In the solving processes of the two students, a NNC emerged for the first time after more than half an hour:

Tim It would be the best if we had a function equation right' (.),well if one could say exactly ,f of $x$ equals (...), wait ,whats that' (points at the sheet), no ,thats not a sum. (p. 247, transcription key in the appendix)

Here Tim shows a NNC for a function equation which in his view would be able to help in solving the continued fraction task. But there was a long epistemic process preceding this step. Since there was no clear NNC earlier, not even for the construct of the space of places they had built before, it was not clear what drove this process. As a driving force we identified what we called a general epistemic need (GEN). This GEN turned out to be a boundary object that could be interpreted by each of the two theory teams (Akkerman and Bakker 2013). A boundary object is an object or a concept at the boundary of two social cultures that can be understood from both cultures. From the AiC view, the GEN was a kind of individual desire to understand more about such a fraction. This GEN sometimes became more concrete, for example when one student felt the need to be more precise or to generalize. This was shown in his epistemic actions. The NNC can then be regarded as a specific GEN. It emerges when the exploration provides a collection of concrete ideas that help the students to focus on a specific construct, which they assume would help them to solve the 
problem. From the IDS view, such a GEN emerges as a socially shared necessity in order to proceed within a social group. This GEN could also become more specific in some situations, for example, when the students searched for an example because they needed to be more concrete in their explorations. This social situation may also result in an individual expression of a NNC that can be taken up by other students.

\subsubsection{Reflecting on the Case Study}

The fifth step in the cross-methodology is a reflection phase on the whole process after discussing the results.

In an epistemic process a GEN may lead to an incomplete mathematical situation from which situational interest emerges when the students enter into an epistemic situation. For example, in the task above the students identified two subsequences both of which seemed to approximate the number 2 . This observation puzzled the students and they wanted to come to know how this approximation may happen depending on the length of the continued fractions. Thus, the students became deeply involved in further explorations, making sense of a kind of approximation they had not seen before. As they proceeded in sense making they showed situational interest through their involvement and sense making. According to Knorr Cetina the approximation turned into an epistemic object that the students wished to clarify. This interest pushed the epistemic process, producing a further GEN, from which emerged, in turn, incomplete situations of how the convergence to 2 can be proved. Such incompleteness called for completion again and pushed the students' investigation further.

Let us now reflect on the networking of theories, the use of theories, and methodology. In this phase the researchers clarified how the individual and social processes of constructing knowledge may be related: From the view of the social construction of knowledge this epistemic process consisted of a flow of ideas built upon each other and distributed among the students. Such a flow of ideas can be taken as a phase of gathering mathematical ideas. As a social process it provides opportunities for the individual learner to recognize relevant previous constructs. While within this process the students socially connect these constructs or ideas while working with the tasks they may build-with them individually. The process may lead towards structure seeing in which individuals construct new knowledge (Bikner-Ahsbahs and Kidron 2015, p. 248). This result indicates that the two theories share a boundary concept, but the result does allow for synthesizing the theories because a shift of attention is necessary when interpreting the general epistemic need from one of the two theoretical perspectives. 


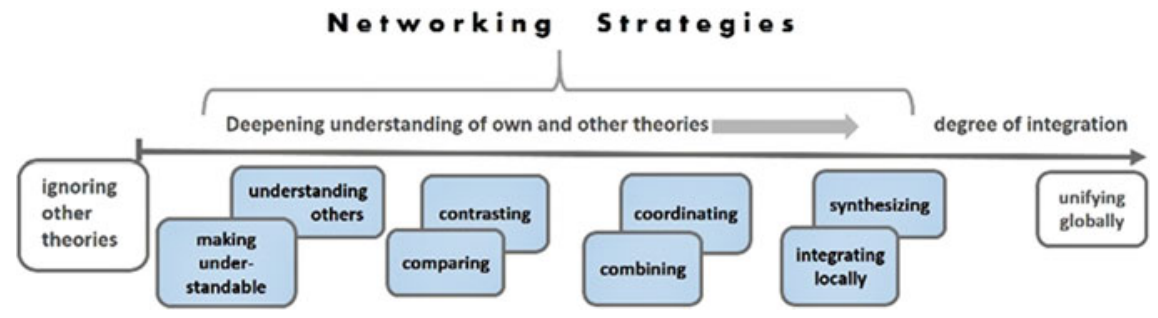

Fig. 7.14 Networking Strategies (Bikner-Ahsbahs et al. 2016, p. 34, revised version from Bikner-Ahsbahs and Prediger 2010, p. 492)

\subsection{What Is Networking of Theories About?}

We now step back to consider what the networking of theories is about. In this case study we wanted to use two theories to answer our research question of how the need for a new construct and situational interest are related. For that reason we related the two theories using networking strategies. These are the pairs of strategies (see Fig. 7.14), ordered according to increasing potential of integration.

The two poles in the landscape in Fig. 7.14, namely, ignoring other theories and unifying theories globally, do not belong to the networking strategies. The networking of theories consists of building relations between theories based on concrete research. In our example, we first made the two theories understandable and required the reader to understand the theories described by the theoretical concept developed by Radford. In the landscape of networking strategies this pair of strategies is the starting point to undertaking a networking process in order to be able to identify the specificities of the theories. We then compared and contrasted the theories by identifying commonalities and differences. Clarifying exactly what underlies the differences between the two theories provides an additional in-depth understanding of both theories. The third strategy encompasses combining and coordinating. In our case this was done in order to answer the research question "How are the need for a new construct and situational interest related?" by means of research involving a coordinated methodical procedure of exchange. The research resulted in a new concept, the general epistemic need (GEN) that allowed for a local integration in that the concept turned out to be a boundary objects that could be understood from the two perspectives. The research did not result in more than that. Synthesizing would require building a new theory in which the two theories are embedded. Such a theory would have to dissolve the difference between the individual and the social. 


\subsection{Final Comments}

This paper not only describes the research pentagon but also illustrates how it can be used as a diagram with which a researcher, especially an early career researcher, may think-about research. It is not meant to act as a rigorous concept; it rather is a tool that allows an expression of the current status of research, which then may be worked with creatively. It may function as an individual pentagon to be further developed and restructured to support the epistemic practice of inquiry in research. At the beginning it seems useful to just focus on each aspect separately, then to relate them to each other, and finally to consider several aspect at a time. Where to begin depends on the research to be done. As shown in the networking case, the pentagon can also be used as an analytical tool making visible how the networking of theories takes place in a piece of research and what kinds of relations are built in research. The double diagram shows that the networking of theories goes beyond triangulation, in that it provides a process of boundary crossing with the potential to identify boundary objects as a link between cultures of theories. Note that the networking of theories is not an aim in itself; researchers should have good reasons why they want to follow this process. In the case study above the reason was the need to make use of the concepts, reciprocally each to each, from the other theory, because we felt that the two concepts, need and interest, could inform each other, theoretically and practically in teaching.

Acknowledgements I thank Dilan Şahin-Gür for her contribution to this chapter, Marit Hvalsøe Schou, Ivy Kidron and Tommy Dreyfus for their consent to refer to research we conducted together, and Tommy Dreyfus for reading and offering insightful feedback to this chapter.

The research on which this chapter is based was partially supported by the German-Israeli Foundation for Scientific Research and Development (GIF) under grant number 946-357.4/2006.

\section{Appendix}

\section{An Exercise: Group Work on the Transcript of Tim and Matt}

In this exercise readers who want to know about how the networking of theories is practiced may follow the instruction and use the extended transcript to obtain own experience with the networking of theories taking up the two example theories.

\section{A Networking Exercise}

Work in pair and decide who is taking over the view of Abstraction in Context (AiC) and who is taking over the view on Interest-Dense Situations (IDS). The research question for the networking case is: How does the need for a new construct (NNC) relate to the emergence of situational interest shown when students become involved in the task and express that something is meaningful to them. The research question for the $\mathrm{AiC}$ view is, how and where does the 
NNC emerge within the process of constructing knowledge. The research question for the IDS view is, how and where is situational interest expressed during the process of knowledge construction. Go through the transcript:

- deciding cooperatively about the part of the transcript to be analyzed,

- separate processing, analyzing separately this part from each perspective addressing the emergence of the NNC on the one hand and of situational interest on the other during the process of constructing knowledge,

- exchange of the results and working with the results from the other view, exchanging the analysis results and commenting on them,

- reworking own results, re-analyzing the part of the transcript from the own perspective in the light of the results from the other view, and finally,

- meet collaboratively and aim at building consensus about the work done.

The following discussion occurred about half an hour after the students started working on the above task about a continued fraction.

1. I: And ,f of ,one million'

2. $\mathrm{T}: \mathrm{Ohm}$

3. M: (sighs) $\mathrm{F}$ of one million

4. /T: we would have to cal- calculate now , whats the root of one million ,and then round it down

5. /M: what kind of'

6. I: You- ,you really dont need to do it accurate now now

7. /M: no, now we are doing it (laughs)

8. /I: (spoken simultaneously) ok.

9. M: Thousand

10. /T: (spoken simultaneously) is thousand, so exact thousand the set, of the space of places

11. I: Hmmh

12. T: So th-

13. I: And how would $\mathrm{f}$ of one million and one look like'

14. T: Ohm that would still be a spa-, that is just the set of the space of places

15. /M: so one (looks at the calculator), ah never mind

16. /T: we just cant the- ,still thousand, until, one thousand and one results

17. /M: but what we do know in any case is ,that ohm there is a one in front of the point ,well not for one thousand and one ,for thou- for one-

18. /T: yes, for one thousand and one there is a one in front of the point, well no wait yes ,a two

19. /M: thats an odd number, yes

20. T: Two point, ,zero zero zero zero zero

21. /M: yes because its an odd ohm, place 
22. T: Yes ,so its very close to two already

23. M: Yes

24. T: Those are about a hundred zero or something (laughs), and then its a different,another number

25. (.)

26. M: Yes

27. T: Yes

28. I: And how would it work then'

29. T: I would say it keeps on going like that

30. /M: its an infinite number

31. /T: and it keeps on leaning closer to zero- ,closer and closer to two ,both numbers

32. M: Yes exactly and sometime it get's

33. /T: but becomes never two there are always infinite zeros

34. /M: yes its infinite thats just it

35. /T: at the end are infinite zeros, or infinite nines ,and then there is something.

36. /M: And then one could conjecture that

37. /T: the whol $(e)-$

38. /M: we can insert infinite (1:05:07.9)

39. $\mathrm{T}$ : When we insert infinite

40. /M: (not understandable) will always be the same

41. T: If- ,if you insert infinite, its theoretically two

42. M: Yes on-,yes exactly. ,then it would be two,because one

43. /T: because it has as many

44. /M: one point nine ,ey, what was the number again' (laughs), one point nine period'

45. T: Yes

46. M: Equals two then

47. T: Yes-,equals about two.

48. M: Equals two.

49. T: So close- , ah ok.

50. M: So one found out that ohm- ,on $(e)$ - one say ,our teacher told us that ohm- , one point nine period equals two.

51. I: Ok

52. /M: or wasnt it zero point nine nine

53. T: Because one , one one ninth , is namely, one point nine nine nine nine nine nine nine nine ,a-nd two.,because one plus nine ninth is precisely two ,but nine , one ninth ,is zero point one one one one one

54. /M: yes but then, do you want to do nine ninth , that would be two

55. T: Yes

56. (.)

57. I: Ok.

58. T: Theoretically (M laughs) 
59. I: Could you maybe some-how formulate the conjecture ,a little bit'

60. M: Yes ,there we write that ohm, what we conjecture

61. T: Yes ,otherwise we just write down $\mathrm{f}$ of infinite equals two and expla- , explaining we do here then (points at the sheet)

62. I: Yes exactly

63. T: Right'

64. /I: afterwards we can ,you have already written so much.

65. /T: we write (speaks while writing) ,f of infinite (.) ,equals two

66. I: Hmmh

67. (..)

68. M: Ok. (laughs) That was a short exercise (laughs, looking at T)

69. I: Yes ,now that were ,yes ,a lot of conjectures ,that you have done (laughs)

70. T: So.

71. M: (grabs inside of the stack of exercises) Now comes explaining (all three laugh)

72. T: That will be more difficult (laughs)

73. I: I ,I find your last aspect now the most interesting

74. M: Yes ,that really is interesting on how-

75. T: Yes ,theoretically it keeps on leaning closer to two

76. /M: yes

77. T: When (or "if”) you look at it closely, it never gets two ,even if there are infinite nines ,behind it there is always ,seven three two ,whatever. ,it can be everything (.) ,the numbers behind it ,we have not looked at it ,possible that they have a pattern too ,but ,I see- ,personally I dont see anything (M laughs)

78. I: Look kinda wild, yes.

79. T: Yes.

80. I: Now could you (.), explAIN it somehow, why that somehow (bends forward to the notes of the students)

81. /M: Well we look, lets look at the beginning again here

82. T: It would be the best if we had a function equation right' (.), well if one could say exactly ,f of $x$ equals (...), wait ,whats that' (points at the sheet) ,no ,thats not a sum (not understandable)

\section{Transcription Key}

\begin{tabular}{|c|c|}
\hline $\mathrm{S}(\mathrm{s}), \mathrm{T}$ & student(s), teacher \\
\hline EXECT & loud voice \\
\hline exect & with stressed voice \\
\hline$\overline{e-x}-\mathrm{a}-\mathrm{c}-\mathrm{t}$ & prolonged \\
\hline exact. & dropping the voice \\
\hline exact' & raising the voice \\
\hline ,exact & with a new onset \\
\hline exact- & voice remains suspended \\
\hline$(),.(.).(\ldots)$ & $1,2,3$ seconds pause \\
\hline$(\ldots)$ & more than $3 \mathrm{sec}$ pause \\
\hline
\end{tabular}


(5sec) 5 seconds pause, if necessary

(gets up) nonverbal activity, the duration of non verbal activity need not be fixed unless it is special, a pause of 2 seconds afterwards (..), interpreted (slow)

(exact??) assumed utterance

\section{References}

Akkerman, S. F., \& Bakker, A. (2013). Boundary crossing and boundary objects. Review of Educational Research, 81(2), 132-169.

Batanero, M. C., Godino, J. D., Steiner, H.-G., \& Wenzelsburger, E. (1994). The training of researchers in mathematics education: Results from an international survey. Educational Studies in Mathematics, 26(1), 95-102.

Baumert, J., \& Lehmann, R. (1997). TIMSS-Mathematisch-naturwissenschafticher Unterricht im internationalen Vergleich [Instruction in mathematics and science on an international comparison level]. Opladen: leske + Budrich.

Bikner-Ahsbahs, A. (2005). Mathematikinteresse zwischen Subjekt und Situation. Empirisch begründete Konstruktion einer Theorie interessendichter Situationen. [Interest in mathematics between subject and situation. Building bricks for an interest theory in mathematics education.] Hildesheim: Verlag Franzbecker.

Bikner-Ahsbahs, A. (2015). How ideal type construction can be achieved: An example. In A. Bikner-Ahsbahs, C. Knipping, \& N. Presmeg (Eds.), Approaches to qualitative methods in mathematics education-Examples of methodology and methods (pp. 137-154). Advances in Mathematics education. New York: Springer.

Bikner-Ahsbahs, A. (2016). Networking of theories in the tradition of TME. In A. Bikner-Ahsbahs, A. Vohns, R. Bruder, O. Schmitt, \& W. Dörfler (Eds.), Theories in and of mathematics education (pp. 33-42). ICME-13 Topical Surveys. Switzerland: SpringerOpen.

Bikner-Ahsbahs, A., \& Halverscheid, S. (2014). Introduction to the theory of interest-dense situations. In A. Bikner-Ahsbahs \& S. Prediger (Eds.), Networking of theories as a research practice in mathematics education (pp. 97-112). Advances in mathematics education series. Dordrecht: Springer.

Bikner-Ahsbahs, A., \& Kidron, I. (2015). A cross-methodology for the networking of theories: The general epistemic need (GEN) as a new concept at the boundary of two theories. In A. Bikner-Ahsbahs, A., Knipping, C., \& Presmeg, N. (Eds.), Approaches to qualitative research in mathematics education: Examples of methodology and methods (pp. 233-250). Advances in mathematics education series. Dordrecht: Springer.

Bikner-Ahsbahs, A., \& Prediger, S. (2010). Networking of theories-An approach for exploiting the diversity of theoretical approaches. In B. Sriraman \& L. English (Eds.), Theories of mathematics education: Seeking new frontiers (pp. 479-512). Advances in mathematics education series. Dordrecht: Springer.

Bikner-Ahsbahs, A., \& Prediger, S. (Eds.) (2014). Networking of theories as a research practice. Advances in mathematics education series. New York: Springer.

Boaler, J., Ball, D. L., \& Even, R. (2003). Preparing researchers for disciplined inquiry: Learning from, in, and for practice. In A. Bishop \& J. Kilpatrick (Eds.), International handbook of mathematics education (pp. 491-521). Dordrecht: Kluwer.

Davydov, V. V. (1972/1990). Soviet studies in mathematics education: Vol. 2. Types of generalization in instruction: Logical and psychological problems in the structuring of school curricula (J. Kilpatrick, Ed., J. Teller, Trans.). Reston, VA: NCTM. 
Dreyfus, T., Hershkowitz, R., \& Schwarz, B. B. (2015). The nested epistemic actions model for abstraction in context: Theory as methodological tool and methodological tool as theory. In A. Bikner-Ahsbahs, C. Knipping, \& N. Presmeg (Eds.), Approaches to qualitative research in mathematics education: Examples of methodology and methods (pp. 185-217). Advances in mathematics education series. Dordrecht: Springer.

Freudenthal, H. (1991). Revisiting mathematics education: China lectures. Dordrecht: Kluwer.

Haser, Ç. (2018). Key experiences in becoming an independent mathematics education researcher. Canadian Journal of Science, Mathematics and Technology Education, 18(1), 29-41.

Hershkowitz, R., Schwarz, B. B., \& Dreyfus, T. (2001). Abstraction in context: Epistemic actions. Journal for Research in Mathematics Education, 32, 195-222.

Hiebert, J., Stigler, J. W., \& Manaster, A. B. (1999). Mathematical features of lessons in the TIMSS video study. Zentralblatt für Mathematikdidaktik (ZDM), 99(6), 196-201.

Hoffmann, M. H. G. (2005). Erkenntnisentwicklung. Ein semiotisch-pragmatischer Ansatz [Recognition development. A semiotic-pragtmatic approach]. Frankfurt a.M.: V. Klostermann.

Kidron, I., \& Bikner-Ahsbahs (2015). Advancing research by means of the networking of theories. In A. Bikner-Ahsbahs, C. Knipping, \& N. Presmeg (Eds.), Approaches to qualitative research in mathematics education: Examples of methodology and methods (pp. 221-232). Advances in mathematics education series. New York: Springer.

Kidron, I., Bikner-Ahsbahs, A., Cramer, J., Dreyfus, T., \& Gilboa, N. (2010). Construction of knowledge: Need and interest. In M. M. F. Pinto \& T. F. Kawasaki (Eds.), Proceedings of the 34th Conference of the International Group for the Psychology of Mathematics Education (Vol. 3, pp. 169-176). Belo Horizonte, Brazil: PME.

Kidron, I., Bikner-Ahsbahs, A., \& Dreyfus, T. (2011). How a general epistemic need leads to a need for a new construct: A case of networking two theoretical approaches. In M. Pytlak, T. Rowland, \& E. Swoboda (Eds.), Proceedings of the 7th Congress of the European Society for Research in Mathematics Education (pp. 2451-2461). Rzeszów, Poland: University of Rzeszów.

Knorr Cetina, K. (2001). Objectual practice. In T. R. Schatzki, K. Knorr Cetina, \& E. von Savigny (Eds.), The practice turn in contemporary theory (pp. 175-88). London and New York: Routledge.

Liljedahl, P. (2018). Mathematics education graduate students' thoughts about becoming researchers. Canadian Journal of Science, Mathematics and Technology Education, 18(1), $42-57$.

Lotman, Y. M. (1990). Universe of the mind. A semiotic theory of culture. Bloomington: Indiana University Press.

Malle, G. (1993). Didaktische Probleme der elementaren Algebra. Braunschweig and Wiesbaden: Vieweg Verlag.

Mason, J., \& Waywood, A. (1996). The role of theory in mathematics education and research. In A. J. Bishop, et al. (Eds.), International handbook of mathematics education (pp. 10551089). Dordrecht: Kluwer.

Mitchell, M. (1993). Situational interest: Its multifaceted structure in the secondary school mathematics classroom. Journal of Educational Psychology, 85(3), 424-436.

Nardi, E. (2015). "Not like a big gap, something we could handle": Facilitating shifts in paradigm in the supervision of mathematics graduates upon entry into mathematics education. International Journal of Research in Undergraduate Mathematics Education, 1(1), 135-156.

Peirce, C. S. (1931-1958). Collected papers (Vol. I-VIII). Cambridge: Harvard University Press.

Radford, L. (2008). Connecting theories in mathematics education: Challenges and possibilities. Zentralblatt für Didaktik der Mathematik-The International Journal on Mathematics Education, 40(2), 317-327.

Radford, L. (2012). On the growth and transformation of mathematics education theories. Paper presented at the International Colloquium The Didactics of Mathematics: Approaches and Issues. A Homage to Michèle Artigue. Université de Paris VII. May 31 to June 1, 2012. http:// luisradford.ca/publications/ (14.1 pp. 1. 2018). 
Reys, B., \& Reys, R. (2017). Strengthening doctoral programs in mathematics education: A continuous process. Notices of the American Mathematical Society, 64(4), 386-389.

Sahin-Gür, D., \& Prediger, S. (2018). "Growth goes down, but of what?" A case study on language demands in qualitative calculus. In E. Bergqvist, M. Österholm, C. Granberg, \& L. Sumpter (Eds.), Proceedings of the 42nd Conference of the International Group for the Psychology of Mathematics Education (Vol. 4, pp. 99-106). Umeå: PME.

Schmitz, T. H., \& Groninger, H. (2012). Werkzeug-Denkzeug. Manuelle Intelligenz und Transmedialität Kreativer Prozesse [Tool-tool to think with: Manual intelligence and transmediality]. Bielefeld: transcript verlag.

Schou, H. M., \& Bikner-Ahsbahs, A. (submitted). Unpacking hidden views: Seven ways to treat your formula.

Siller, H.-S., \& Roth, J. (2016). Herausforderung Heterogenität. Grundvorstellungen als Basisund Bezugsnorm: das Beispiel Terme [Challenge of hetrogeneity: Basic images as fundmental reference norm: The example of algebraic expressions]. Praxis der Mathematik in der Schule $70,2-8$.

Treffers, A. (1987). Three dimensions. A model of goal and theory description in mathematics instruction: The Wiskobas project. Dordrecht: D. Reidel Publishing Company.

Open Access This chapter is licensed under the terms of the Creative Commons Attribution 4.0 International License (http://creativecommons.org/licenses/by/4.0/), which permits use, sharing, adaptation, distribution and reproduction in any medium or format, as long as you give appropriate credit to the original author(s) and the source, provide a link to the Creative Commons license and indicate if changes were made.

The images or other third party material in this chapter are included in the chapter's Creative Commons license, unless indicated otherwise in a credit line to the material. If material is not included in the chapter's Creative Commons license and your intended use is not permitted by statutory regulation or exceeds the permitted use, you will need to obtain permission directly from the copyright holder. 